\title{
ON COOPERATION AND COMPETITION
}

\author{
Chris Wild \\ University of Auckland, New Zealand \\ c.wild@auckland.ac.nz
}

We explore the tensions between cooperation and competition in the context of improving the content, delivery and penetration of statistics education. We explore models for increasing the numbers of students studying statistics and how working in teams can increase the quality of the teaching that students experience.

\section{INTRODUCTION}

We have had lots of good people embracing "cooperation" this week with some wonderful and inspiring stories. "Cooperation” ... "working cooperatively.” It sounds so positive, noble, life affirming. It sounds like the sort of thing any good person would want to embrace. It sounds like the sort of world I want, like the sort of person I want to be. After a week in paradise, however, we are nearly ready to return to the real worlds that we inhabit day-to-day. Here other, cynical phrases circulate, like "nice guys finish last." In our day-to-day worlds we frequently compete. We compete for funding, for positions, for reputation, for promotions, for curriculum share, for students, for our student's attention and thinking time. Our textbook writers compete for adoptions. We are often caught in a zero-sum resource-allocation net where the only way for someone to get more is for others to get less. Cooperation and competition - how do we reconcile these things? Is it even possible to reconcile these things?

As we proceed you will probably find that I emulate, rather too frequently, the American Founding Fathers in the Declaration of Independence, "We hold these truths to be self-evident." My first self-evident truth is that there are areas where it is vital to be a successful competitor. For example, educational programmes and Departments that cannot attract good people to work in them and cannot attract students to study in them whither and die. To be able to attract good teachers and students we have to be doing well relative to others, i.e., to be competitive. The fact that we have to compete at some level with some one is a given. The interesting questions are, "In what areas do we have to compete?" "Who do we compete with?" "How can we compete with them successfully?”

We have seen some stunning examples this week of the positive power of cooperation and you'll see more in this talk. Cooperation is, I believe, our most powerful tool for advancing quality and productivity, and for building an environment that stimulates creativity. So, my second self-evident truth is that, just as the need to compete is a given, so too is the need to cooperate. The interesting questions here are, "What are my 'communities of common interest'?" "Who can I cooperate with?" "How can I cooperate with them in a way that confers the greatest advantages to all?”

My third self-evident truth is that a community of common interest will benefit if it can organise itself in such a way that those making up that community also benefit personally by cooperating. To do well in our careers, for example, each of us needs to look good to "superiors" - those who have influence over our destinies. There are problems with this around cooperation. Teachers can just think "group projects." And it is not enough just to have warm, fuzzy, contented people cooperating. We also need ambitious, driven people to want to cooperate because of their propensity to get things done. It is easy to see the benefits of cooperation for a cause or for a project. What really taxes the intelligence is how also to deliver personal benefits for the cooperators.

So, in summary, we have "Competition: Where? With whom? How?" "Cooperation: Where? With whom? How?" And, "How can we organise cooperation so that each cooperator can benefit personally?”

\section{APPLICATION TO STATISTICS EDUCATION}

I want to explore the notions of competition and cooperation in the context of advancing the interests of statistics education. I am going to concentrate on undergraduate (first university 
degree) statistics teaching. Whereas there is real competition for quality graduate students, particularly between elite schools, the situation at the undergraduate level is quite different and the potential to change the landscape is considerably higher. For some of the above competitioncooperation questions I have tentative answers. Finding answers to the rest of these questions will be your homework. Your deadline is ICOTS-8 in 2010 but early submission of your assignments is strongly encouraged.

For most ICOTS participants I am sure that the following are largely givens.

- Increasing the levels of statistical thinking and expertise in the population benefits society

- Increasing the quality and penetration of statistics education is good

Most of us have a commitment to this enterprise that is almost religious. We want to convert the unbelievers. We already know ourselves that improving the content, delivery and penetration of statistics education is a worthy cause deserving of our time and intelligence, our entrepreneurship and research. Building from this foundation, I hope also to convince you that both societal altruism and self-interest lead us towards the same downstream courses of action.

In Wild (1994), I discussed something I called the "rule of 100." What is it? "For every theoretical statistician that society needs, it needs 100 applied statisticians and for each one of those applied statisticians, it needs 100 non-statisticians who can recognise where the applied statisticians' skills are required. ..... You might argue about the power of ten, but it is hard to argue with the pattern. We need to recognise this reality in designing educational strategies and in designing marketing strategies." A critical omission from the above, as everyone will recognize in 2006, is the need for basic levels of statistical literacy for all.

It is to the advantage of us all if more of the best and brightest come into statistics education systems and leave them better educated, with better developed thinking skills, and a greater appreciation for the power of statistics. Better and better-educated people have a greater impact, both practical and intellectual, and increase the demand for the perceived sources of their success. But statistics is not just for an elite. Society at large will benefit if a broad cross section of students emerge statistically literate and with an appreciation for the power of statistics and the desirability of decisions being made on the basis of solid data. Altruism and professionalism demand that we put in place educational structures that address these needs, that in designing programmes and structures we try to deliver the greatest benefits for the greatest numbers, that we deliver our teaching in ways that are most likely to lead to the long-term retention of the most important messages and skills, and that we do research that helps us to achieve these goals.

"When I grow up I want to be a statistician!” It would be nice but it just doesn't happen, does it? The most critically important element for the future health of our discipline is an ample supply of very bright young minds entering it. In any jurisdiction that I know, students entering university with a burning desire to study statistics are rarer that hen's teeth. Statisticians have always operated on what is, at base, a conversion model to draw people into the discipline. Traditionally we have converted mathematicians. For many of my generation of mathematics students, a big appeal of statistics as we headed into graduate study was the security of a wider range of career options. We were "mathematical pragmatists."

Today, most of us are facing a dwindling supply of mathematics students and the evergrowing range of exciting well-paid competing options is siphoning off most of the remaining mathematical pragmatists before they even enter university mathematics. The corollary is that, with the possible exception of a few elite schools, university programmes in statistics built solely on converting mathematicians are doomed to decline in the medium term. So what can we do? Wait and pray that retirement arrives before downsizing and redundancy? When there are insoluble problems with a supplier, you have to find alternate sources of supply.

In the 1990s, the American Statistical Association had working parties laying down guidelines for undergraduate statistics programmes. This is valuable work but what it produces are guidelines and not prescriptions. One of the dangers of such guidelines, and also benchmarking, external examiners, and other forms of striving for common "standards" is that it can lead to an unfortunate uniformity that stifles entrepreneurship. What it is possible to achieve in a given environment depends on funding models, patterns of demand, institutional history in terms of who has come to own what and why, relationships with other players in the institution and rules governing programmes. Much of what determines where our opportunities are is local, 
and so must the solutions be. I have a very organic conception of the way forward which goes, "get your roots in where you can and try to establish something that can grow there." And in most places, the vehicle will be more effectively utilizing the appeal and delivery of applied statistics.

A model that is working at a number of universities including my own feeds off service teaching. I think of it a service-conversion model. The largest undergraduate statistics programme in the US by some way is at Brigham Young University. It graduates about 150 statistics majors a year and it too is built on a service-conversion model. Many statistics (and mathematics) groups around the world depend heavily on statistical service teaching for their financial viability. The new trick we need to master is to take the opportunities provided by that to attract students sitting in service courses and retain sufficient of them all the way through to postgraduate level. We are not talking of an attack which will damage other programmes. We want to attract good numbers of students into learning a little more statistics than they do now and much smaller but still significant numbers, drawn from right across the spectrum, into choosing statistics as their major discipline.

There are many things that have to be in place to make this work. First you have to get and keep substantial levels of service teaching with all that entails in terms of satisfying clients and building relationships. Then you have to do the teaching exceedingly well. You are, after all, trying to convert students with no prior interest in the subject sitting in introductory statistics courses - courses which in many places have had a reputation as being the most mind-numbingly boring on the planet. Of course it doesn't have to be like this. Some of the most stellar teaching evaluations at the University of Auckland are now coming out of the Department of Statistics. (Not from me I might add. I am a very poor advertisement for the teaching skills in Auckland statistics.)

You also have to structure programmes in a way that minimizes barriers to progression. Most of our growth in student numbers and the courses they are taking has come in applied rather that theoretical statistics, but that (recall the Rule of 100) is where the greatest need is. Building the theoretical side is slower and a still a work in progress. We do have assets including one young academic who is rating through the roof in the key choke-point theory course. In the conversion game we cannot afford to be dumb about where people are deployed. But if the different environment gives rise to different programmes with differently educated graduates then so be it.

What do others want from our statistics teaching? Numeracy for all? To ensure students gain important life skills? Giving exposure to the mathematical sciences as an intrinsic good and a prerequisite for being called "educated"? That may be true for those responsible for general education components of degrees in the United States and a few idealistic educational theorists, but the only reason my colleagues in other disciplines value statistics enough to require it for their students is to help prepare them to do and read research.

Let us set aside the question about how many of them will actually ever do serious research. It is "preparing for research" that gives us the customers and delivering on that is what will keep them happy. The statisticians' best defence against untrained, inexperienced do-ityourselfers is to be able to get students to the sexiest, most useful, techniques faster and more effectively than they can. For us to do this, however, will require the shedding of a lot of historically accumulated conceptual and mechanical baggage. "You can't teach A without also teaching B, C and D along the way." This has been the poison pill that has killed many a service teaching operation. Woefully, there is also still far too much put-numbers-in-a-formula handcalculator drill going on in low-level statistics teaching. Real researchers use computer packages and concentrate on what it is that they can learn from their data (see Pfannkuch and Wild 2000; Wild and Pfannkuch 1999). Hand-calculation instruction can be justified really only to the extent that it helps establish a concept. Proficiency in hand-calculator and statistical table skills is historical baggage that we should have abandoned long ago. And yet Moore (2005), quoting Lutzer et al. (2002), notes that in the US only $61 \%$ of elementary statistics courses taught by $\mathrm{PhD}$ granting departments of statistics use computing and that the corresponding rate for mathematics departments was only $48 \%$.

Why should statisticians be able to get students in their own and other disciplines to "the good stuff” faster and effectively than anyone else? Simply because the statistical profession can 
and should make it a central focus. Its future depends on it, whereas for others it is a side issue. But it will require in depth analysis and research as to the minimal conceptual underpinnings necessary to successfully operationalise each approach in a research environment. This first step is necessary across the board but is just not happening. Follow-up research is then required into what the most effective educational experiences are to ensure that these conceptual underpinnings are in place. There is enough work here for large numbers of people. It will never be finished because the frontiers are always moving. And then we have to become adept in building in the hooks (interest and curiosity, but overwhelmingly of importance) that have the students wanting to come back for more.

If the hordes were pounding on our door demanding to be let in, we could afford to lay down very stringent mathematical conditions for entry. Entry to our statistical heaven could indeed be through the eye of a mathematical needle. But our world is not like that. It is more realistic to think in terms of bringing in bright people from wherever we can find them and designing our programmes to enable them to succeed, retro-fitting required skills wherever necessary.

We are all operating conversion models of one form or another. We convert comparatively small numbers of students who entered universities thinking they were heading in some other direction. We don't have the benefit of a pre-existing love for the subject so to be really effective in the conversion business our teaching has to be perceived by students to be some of the best they are experiencing, and strike chords in students that makes them to want to come back - including chords that say that statistics is leading us into the future and is not some faint echo from the distant past.

So how does all this relate back to the competition questions? With regard to who we are in competition with, it says that at undergraduate level our real competition is not from statistics educators in other institutions, it is from other disciplines. How should we compete? We should compete by increasing relevance, interest levels and quality.

"Now just play that back again. Student to staff ratios are worsening, administrative loads and accountability compliance-costs are getting impossible, there are incredible pressures for increased research productivity, the time I have left in our day to do anything at all productive is evaporating and you are telling me I have to teach better. How, pray tell, does that work?”

Most of us can't realistically work any harder. The only way forward is to be smarter and we will have to make compromises that sacrifice some of the things we care about. I think there are key parts of programmes where we will have to abandon the ideal of the autonomous teacher who does everything herself.

\section{A COOPERATIVE MODEL AT AUCKLAND}

Wild (1995) described early attempts at Auckland to using quality management ideas and teamwork to put in place systems to deliver continual improvement in our large first-year service courses despite a continual turnover of personnel. We soon realised that to deliver quality we had to adopt a team model rather than a model that relied on individuals, however brilliant, working independently. Having one section of one course taught superbly to one group of students in one year by a truly outstanding teacher is of little help in achieving continuous quality improvement through time in the larger system. Our aim was to find ways to seal enhancements permanently into the system as a whole so that the courses improved each time they were taught, regardless of who taught them.

It has been a long evolution starting from a simple sharing and discussion culture to the current state where individually-developed teaching materials have been abandoned in favour of working collectively on a common product used by all. There are some competitive pride issues to be set aside here. We try to capture as much as possible of what makes our best teachers good and transfer that to everyone in the group now and for the future. So it involves sharing all your best ideas and favourite tricks with the rest of the team so everyone can take advantage of them. It became clear also that for a system that can retain the most important contributions from those who move on, turnover is a boon rather than a burden. It continually revitalises the team with fresh ideas, enthusiasm and creativity. 
With that we have been able to build a very flexible, well-integrated learning environment with high-quality animated PowerPoint Lecture Slides, a full set of PowerPoint Lectures on CD with complete with narrated soundtrack (we also produced a Mandarin soundtrack), extensive Computer Manuals and Tutorials with narrated screencam movies, Excel Spreadsheets and Applets, video clips, gapped Lecture workbooks, filled-in versions of the same, a large online test bank with extensive feedback, online Forums that get tens of thousands of hits each month, extensive use of online surveys, and experimentation with instant-messaging discussion groups. If time permits we will show you some of the resources so that you get some idea of their quality. There has been recognition of the team's success in the form of several university teaching awards and a national teaching excellence award. The team also finds time for other cooperative activities like being involved in the development of the national curriculum for statistics in schools and running nation-wide outreach activities like the New Zealand CensusAtSchool project and teacher workshops.

This team serves over 3500 students per year. It has a small stable core of people who do much of the teaching and almost all of the development. The team is very productive because they are no longer doing their preparation work in parallel reinventing their own slightly different versions of the wheel. They are working closely together, are regularly in discussion and sparking ideas off one another. The same team model is being used very successfully in our second year applied courses (about 1300 students per year) and we have just started using it in a MBA programme. We are also exploring ways of involving other universities. This way of working is particularly valuable where there is turnover or where you have, from time to time, to use inexperienced people and want to avoid significant drops in the quality of teaching and assessment experienced by students.

But there also are a myriad of unexpected subtle ways in which teamwork can increase quality and creativity. Much of it stems from the way in which smart, committed people who are teaching the same material, regularly discussing their experiences and polishing a common set of resources, continually learn from one another and their environment. It is superb for teacher development.

At an education panel session I organised at the 2005 International Statistical Institute in Sydney, discussion started drifting into an area involving fine distinctions in the English language. One of the panellists, then ISI President-Elect Neils Keiding, stated quite bluntly that this was not appropriate at an international conference. He was probably right to do so. The conversation was going places where the most non-native speakers of English could not follow. It would be more productive, not to mention polite, to concentrate on exploring more inclusive areas. But in teaching, particularly for complex or unintuitive concepts, the subtleties of the language being used can matter enormously. It is not "mere semantics." When it comes to engendering understanding, semantics can be critical. The references and vocabularies that are widely understood change over time and between age and cultural groups. What a male in his 50s thinks a set of phrases conveys can be very different from what 18 year olds receive, if indeed they receive anything at all.

An important thing that different team members bring to any discussion is differently sensitised antenna. Our different life's experiences have developed for each of us areas where we more aware and more sensitive to signals people are putting out than other people are. One of the many places in which this shows up is in awareness about how particular words and phrases are, or are not, received. Working the way this team does, semantic debates are often at a fine level of detail, a level at which we would never think to discuss or even reflect on in the normal course of life or teaching.

The Nike advertising slogan says, “Just do it!” Although energizing it is not a good recipe for successful teamwork. We have gradually learned not to dive into straight into detail but to formulate and agree on broad principles and then operate according to those principles. This confers consistency, but more importantly it helps us to think through what our purposes are and how to accomplish them. It also helps us learn. When something is not working to our satisfaction there are underlying principles or assumptions to review. These assumptions can be improved on and then reapplied across the system. The team has just revised its teaching model and reworked most of the teaching materials largely in response to revisiting questions including, "What is the 
purpose of the lectures and how should what is done in lectures relate to what is done in reading and other materials?" "In gapped workbooks, how should gapping be used so that stimulates thinking and punctuates big ideas rather than just being busywork?" "How should we use our various forms of quizzes to stimulate and reinforce learning?" "How can big ideas be continually reinforced so that they stand out in student's minds?” This was a mammoth task and at the time of writing the results are not in but we all feel that we a quantum improvement has been made.

A widely perceived barrier to using shared resources is the fact that we don't always agree. Most of the excuses we make for needing to do everything ourselves are to preserve personal preferences. Rather than being a problem, areas of disagreement are our best opportunities to learn and improve. If we disagree on what is the best way to do something maybe after an in-depth discussion airing all the pros and cons we can reach consensus. Maybe there is some experimentation or research we can do that would resolve the issue and move it beyond the preserve of personal prejudice. We should isolate and debate our differences, find ways to resolve and learn from them and then move on to the next learning opportunity.

\section{CONCLUSIONS}

Cooperation and competition - how do we reconcile these things? There are no easy answers. It is a complex world and there are always many competing priorities and tradeoffs to be thought through.

But in the larger scheme of things it is not common that we statistics educators are truly in competition with one another. Rather than viewing ourselves as competitors, we should view ourselves as co-conspirators in the noble cause of improving the content, delivery and penetration of statistics education world wide. The health of the discipline of statistics is best fostered by a good inflow of bright young minds. To achieve that we need to be in the conversion business. It is a business in which we have to be very good and very clever to succeed. It requires both entrepreneurship and research. We cannot lift the quality of our offerings sufficiently by working harder. We are already working about as hard as we can. The only way forward is to borrow strength from one another through cooperation.

Bismark, the German statesman said, "Politics is the art of the possible." Well so too is education. Let us not allow historical baggage and tunnel vision blind us to what the possibilities are. Let us not allow ourselves to be overly reliant on received wisdom about universally "right" ways of delivering statistical education. Let us have the self-confidence to seek local solutions, to recognise and plant seeds that can take root, grow and flower in the stony soils where we live.

\section{REFERENCES}

Lutzer, D., Maxwell, J. and Rodi, S. (2002). Statistical Abstract of Undergraduate Programs in the Mathematical Sciences in the United States. Providence: American Mathematical Society.

Moore, D. (2005). Quality and relevance in the first statistics course. International Statistical Review, 73, 205-206.

Pfannkuch, M. and Wild, C. (2000). Statistical thinking and statistical practice: Themes gleaned from interviews with professional statisticians. Statistical Science, 15, 132-152.

Wild, C. (1994). On embracing the 'wider view’ of statistics. The American Statistician, 48, 163171.

Wild, C. (1995). Continuous improvement of teaching: Case Study in a large statistics course. International Statistical Review, 63, 49-68.

Wild, C. and Pfannkuch, M. (1999). Statistical thinking in empirical enquiry (with discussion). International Statistical Review, 67, 221-266. 